\title{
Prevention of Alzheimer's disease in high risk groups: statin therapy in subjects with PSEN1 mutations or heterozygosity for apolipoprotein $E \varepsilon 4$
}

\author{
Daniel A Pollen*1, Stephen Baker², Douglas Hinerfeld ${ }^{3}$, Joan Swearer', Barbara A Evans ${ }^{4}$, James E Evans ${ }^{4}$, Richard Caselli ${ }^{5}$, \\ Ekaterina Rogaeva ${ }^{6}$, Peter St George-Hyslop ${ }^{6,7,8}$ and Majaz Moonis
}

\begin{abstract}
Because cerebrospinal fluid (CSF) abnormalities in presymptomatic subjects with PSEN1 (presenilin 1) mutations may be observed 4 to 12 years prior to the estimated age at onset, it is possible to test putative therapies on the CSF analytes that correlate with neurodegeneration during this presymptomatic window of clinical opportunity. It is also possible to test the same therapy on a comparison group with increased risk status conferred by both hyperlipidemia and heterozygosity for apolipoprotein $E \varepsilon 4$. To our knowledge, the only putative therapy thus far tested in such a common design has been statin therapy. The results of these tests show increases in soluble amyloid precursor protein (SAPP)a correlating with statininduced decreases in serum cholesterol levels in the non-PSEN1 subjects. This result could be one functional correlate for part of the substantial risk reduction for late onset Alzheimer's disease recently reported in the Rotterdam study, a large, long-term prospective statin trial. Statin therapy significantly decreased both $\mathrm{SAPPa}$ and SAPP $\beta$ in presymptomatic PSEN1 subjects. Initially, elevated phospho-tau levels in PSEN1 subjects did not further increase during the 2 to 3 years of statin therapy, possibly indicative of a prophylactic effect. These results suggest that large and longer term trials of statin therapy correlating changes in CSF biomarker levels with clinical course may be warranted in both presymptomatic PSEN1 and non-PSEN1 subjects.
\end{abstract}

*Correspondence: pollend@ummhc.org

'Department of Neurology, University of Massachusetts Medical School,

55 Lake Avenue N, Worcester, MA 01655, USA

Full list of author information is available at the end of the article

\section{Introduction}

To date, there have been no systematic treatment studies on subjects with presenilin (PSEN) mutations [1] who inherit an autosomal dominant form of early onset familial Alzheimer's disease (AD). The principal objective of this review is to summarize the existing published pilot studies that address the issues of presymptomatic intervention in early onset familial AD and to compare these results with analogous treatment studies in hyperlipidemic subjects who are heterozygous for apolipoprotein $\mathrm{E}_{\varepsilon} 4$ (ApoE\&4). Our decision to focus on studies of presymptomatic rather than symptomatic subjects was based on the premise that most putative therapies for $A D$ are likely to have more demonstrable effects on normal subjects compared to those with overt $\mathrm{AD}$ whose brains have already been subject to extensive neurodegenerative changes. We also recognize that it is not yet known whether any preventative opportunities that may arise as a consequence of an understanding of the pathogenesis of PSEN1 mutations will be applicable to the vastly larger number of cases of mild cognitive impairment and late onset $\mathrm{AD}$ (LOAD).

Both groups of subjects exhibit early increased brain deposition of amyloid-beta 42 (A $\beta 42$ ), which many researchers [2,3] have proposed is either a direct or intermediary toxic agent in the genesis of the neurodegeneration that subsequently leads to AD. Homozygotes for ApoEє4 are at far greater risk for late onset $\mathrm{AD}$ than are heterozygotes, but we did not identify a sufficiently large enough group of the former to comprise a separate study group. Decreases in cerebral spinal fluid (CSF) A 342 levels precede cognitive decline in subjects with PSEN1 mutations [4,5]. Consequently, in these subjects there is a window of opportunity - estimated as at least 4 to 12 years - to evaluate the ability of any putative prophylactic therapy to decrease, arrest or reverse abnormalities in $A \beta 42$ metabolism many years before clinical symptoms of AD occur. For example, increased levels of CSF phospho-tau and total tau, which are direct measurements that neurodegeneration is 
already occurring, also precede clinical symptoms in PSEN1 carriers $[4,5]$.

\section{Epidemiological and interventional studies of statins and Alzheimer's disease}

Over a decade ago, retrospective epidemiological studies strongly suggested that statin therapy reduced the risk of LOAD [6,7]. More recently, the prospective Rotterdam study [8], which included 6,992 participants followed for a mean of 9 years, has reported that statin therapy substantially reduced the risk of LOAD by almost $50 \%$. Several recent studies of large cohorts have reached similar conclusions $[9,10]$. However, contrary findings were found in other large epidemiological studies [1113]. Methodological differences and the time and extent of the clinical assessments may account for some of these conflicting results and their interpretations $[8,14]$. Prospective studies failing to report a protective effect of statins tended to be characterized by limited durations of follow-up, often 3 years or less, to have a lower number of incident cases and sometimes inclusion of older subjects than in those studies reporting protective effects $[8,14]$.

However, assuming that these protective effects of statins are genuine, it is not yet clear how statins may produce such effects and whether they are more related to the lipid lowering effects of statins or to the 'pleiotropic' effects of statins. Such non-lipid effects of statins with respect to possible risk-reduction of LOAD include the improvement of endothelial function, the reduction of reactive oxygen species and the suppression of inflammatory reactions $[15,16]$. Nor is there yet a consensus as to whether statins with a greater lipophilicity are associated with increased therapeutic benefit. However, the Rotterdam study [8] showed that the protective effects are independent of statin lipophilicity, although there was no reported comparison of the effects of atorvastatin with those of simvastatin, which is the more lipophilic of these two statins.

\section{Mechanisms of putative benefits of statins in Alzheimer's disease}

Other work [17] has suggested that the putative benefits of statins may be attributed to a decrease in cholesterol levels in cellular membranes that would increase membrane fluidity so as to permit $\alpha$-secretase to cleave amyloid precursor protein (APP) along non-amyloidogenic pathways. This would reduce the production of soluble APP $\beta(\operatorname{sAPP} \beta)$ that, in turn, would decrease the amount of substrate available for conversion by $\gamma$ secretase to $A \beta 42$, which is assumed by many to be an agent within a cascade eventually responsible for neurodegeneration [2,3]. Pilot studies to date on presymptomatic subjects with PSEN1 mutations have also assessed the effects of statins as a function of their lipophilicity [18], as will be discussed.

The accessible relevant CSF analytes for such studies are the neurodegenerative triad of $\mathrm{A} \beta 42$, phospho-tau, and total tau, as well as the APP cleavage products SAPP $\alpha$ and $\mathrm{sAPP} \beta$, representing the initial stages of APP metabolism, and cholesterol, its precursor lathosterol, and its metabolite 24(s)-hydroxycholesterol. These lipids serve as surrogate markers for changes in brain levels of these analytes following statin therapy. The descriptive data on our subjects and our experimental results with respect to the above analytes have been published [19].

\section{Recruitment of subjects}

Subjects with presymptomatic PSEN1 mutations were recruited from a large cohort that has participated in our studies since 1985 [20]. Affected members of this cohort carry the C410Y PSEN1 mutation [1]. Approximately 40 at-risk members of this cohort were contacted, of whom roughly half either had already had presymptomatic genetic testing or agreed to such testing. Eight presymptomatic carriers were identified and six of these agreed to participate in the statin studies. Another cohort in the Worcester, Massachusetts area with double PSEN1 mutations (P242H, R352H) was also identified, but only two presymptomatic carriers agreed to participate. Eleven non-PSEN1 subjects who were hyperlipidemic and who, except for two cases, were heterozygous for ApoE\&4 also agreed to participate.

There were hurdles to recruiting subjects that were different in the two cohorts.

A substantial number of at-risk subjects for the PSEN1 mutation did not wish to know their genetic status, a concern expressed by most at-risk subjects in other PSEN1 cohorts [21]. In both groups, some subjects declined to participate based on their reluctance to undergo pre-treatment and post-treatment lumbar punctures. Nevertheless, the obstacle of the limited number of participating subjects was partially compensated for by a series of observations over time for most PSEN1 subjects (6 months, 1 year, 2 years and 3 years after statin treatment in comparison to pre-statin baseline levels). In addition, the application of general linear mixed statistical models [18] coupled with the large effects of statins over time on some of the tested analytes permitted a number of conclusions of robust significance.

The discovery that CSF abnormalities in neurodegenerative markers may occur a decade before clinical symptoms occur provides an opportunity to detect the effects of a putative treatment on CSF analytes many years before a subject would otherwise likely be clinically symptomatic. However, that long clinically asymptomatic duration is a two-edged sword in the sense that major changes in clinical status are unlikely to be easily 
Table 1. Effect of statin therapy with simvastatin or atorvastatin on analytes in non-PSEN1 and PSEN1 subjects

\begin{tabular}{|c|c|c|c|c|c|c|c|c|c|c|}
\hline \multirow[b]{3}{*}{ Analyte } & \multirow{2}{*}{\multicolumn{2}{|c|}{$\begin{array}{c}\text { Primary objective } \\
\text { Statins }\end{array}$}} & \multicolumn{4}{|c|}{ Drug effect } & \multicolumn{4}{|c|}{ Controlled for lipids } \\
\hline & & & \multicolumn{2}{|c|}{ Atorvastatin } & \multicolumn{2}{|c|}{ Simvastatin } & \multicolumn{2}{|c|}{ Atorvastatin } & \multicolumn{2}{|c|}{ Simvastatin } \\
\hline & $\%$ change & $P$-value & $\%$ change & $P$-value & $\%$ change & $P$-value & $\%$ change & $P$-value & $\%$ change & $P$-value \\
\hline \multicolumn{11}{|l|}{ Non-PSEN1 } \\
\hline sAPPa & 7 & 0.013 & - & NS & 13.1 & 0.019 & 9.6 & 0.0082 & 23.7 & 0.0005 \\
\hline SAPP $\beta$ & - & NS & - & NS & - & NS & - & NS & - & NS \\
\hline Phospho-tau & - & NS & - & NS & - & NS & - & NS & - & NS \\
\hline Total tau & - & NS & - & NS & - & NS & - & NS & - & NS \\
\hline AB42 & - & NS & - & NS & - & NS & - & NS & - & NS \\
\hline \multicolumn{11}{|l|}{ PSEN1 } \\
\hline sAPPa & -16.5 & 0.0014 & - & NS & -26.5 & 0.0002 & - & NS & -24.1 & 0.0003 \\
\hline SAPPB & -21.2 & 0.0005 & - & NS & -31.5 & 0.0001 & - & NS & - & NS \\
\hline Phospho-tau & -8.3 & 0.076 & - & NS & - & NS & - & NS & - & NS \\
\hline Total tau & - & NS & - & NS & - & NS & - & NS & - & NS \\
\hline AB42 & - & NS & - & NS & - & NS & - & NS & - & NS \\
\hline
\end{tabular}

Aß42 = amyloid-beta 42; NS, not significant; sAPP, soluble amyloid precursor protein.

detectable unless subjects are studied up to and beyond the average age of risk for a particular kindred. All of our subjects maintained normal neuropsychological status during the relatively brief period of 3 to 4 years over which the studies on CSF analytes were carried out. An insufficient number of subjects remained in the study thereafter to complete longer term assessment of clinical status.

\section{Results of statin therapy on CSF lipid levels}

All the data on the age, sex, PSEN1 status and APOE genotype of our subjects together with statin type and dose over time with resultant serum total cholesterol and low density lipoprotein levels have been published [19]. Additionally, the resultant changes in CSF levels for lathosterol, cholesterol and 24(s)-hydroxycholesterol as a result of statin treatment have also been reported [19]. These CSF lipid levels reached a minimum at 7 months, a return to baseline at 15 months, an overshoot that peaked at 24 months and a drop towards baseline at 36 months. There were no differences in the effects of the two statins with respect to CSF lipid levels nor in PSEN1 versus nonPSEN1 subjects.

\section{Statin therapy and APP metabolism}

The results of statin therapy on levels of CSF sAPP $\alpha$, SAPP $\beta$, phospho-tau, total tau and A $\beta 42$ [18] are shown for non-PSEN1 and PSEN1 subjects in Table 1. The first set of results - called 'Primary objectives' - gives the average effects of treatment independent of statin type. There was a significant increase in SAPP $\alpha$ of $7 \%(P=0.013)$ in the non-PSEN1 subjects and a significant decrease in sAPP $\alpha$ of $-16.5 \%(P=0.0014)$ and in SAPP $\beta$ of $-21.2 \%(P=0.0005)$ in the PSEN1 subjects. The decrease of $-8.3 \%$ in phosphotau in the PSEN1 subjects approaches significance $(P=0.076)$.

When the changes in these same CSF analytes are correlated with the specific drugs ('Drug effect' columns in Table 1), but not with reduction in serum lipid levels, all of the significant changes in SAPP $\alpha$ and sAPP $\beta$ in both subject groups are associated with simvastatin therapy. However, when the data are correlated both with specific drug and the extent of reduction in serum lipid levels ('Controlled for lipids' columns in Table 1), there is a significant increase in SAPP $\alpha$ of $9.6 \%(P=0.0082)$ in the non-PSEN1 subjects on atorvastatin and an increase of $23.7 \%(P=0.0005)$ for non-PSEN1 subjects on simvastatin. However, the difference between the two statins with regard to increased SAPP $\alpha$ in this subject group was not significant.

In the PSEN1 subjects, there was a reduction in SAPP $\alpha$ for the subjects on simvastatin. Moreover, the decrease in SAPP $\beta$ after simvastatin therapy found when not controlling for serum lipid levels was not significant when we controlled for reduction in serum lipid levels. Whether these discordant results indicate that the statin-induced reduction in $\mathrm{APP} \beta$ in this subject group is not dependent on statin dose nor on the statin doserelated reduction in serum lipid levels or to other factors is not clear.

The above results related to APP metabolism were well fitted by general linear methods. However, fitting the temporally diphasic responses of statin-induced changes in CSF lipids required quadratic models. Consequently, it is unlikely that the changes observed in the CSF biomarkers are dependent upon CSF lipid levels. 
Changes in SAPP $\beta$ in the non-PSEN1 subjects were not significant nor were there any significant changes in A $\beta 42$, phospho-tau and total tau.

\section{Effects of statin therapy on CSF analytes}

The increase in SAPP $\alpha$ in the non-PSEN1 asymptomatic subjects without a corresponding decrease in $\triangle A P P \beta$ is at first glance surprising because, in general, it has been assumed that enhanced cleavage of APP by $\alpha$-secretase results in a corresponding decrease in $\mathrm{AAPP} \beta$ because less APP would be available as substrate for its generation [22]. However, that hypothesis, although apparently correct under many circumstances, does not always appear to be valid $[23,24]$. For example, a lack of exclusivity in the production of $A \beta$ and sAPP $\alpha$ has been demonstrated in multiple human cell lines and in a transgenic mouse model in response to various activators [23].

In theory, the increases in sAPP $\alpha$ may be beneficial in risk-reduction of $\mathrm{AD}$ independent of whether there is a corresponding decrease in sAPP $\beta$. For example, Kojro and colleagues [17] in their initial $\alpha$-secretase study noted that increased sAPP $\alpha$ has trophic effects [25], stimulates neurite outgrowth [26], regulates synaptogenesis [27], stabilizes neuronal calcium homeostasis [28], protects hippocampal and cortical neurons against the toxic effects of glutamate and $A B$ peptide [29] and has memory-enhancing effects in normal and amnestic mice [30].

Although our result that there was no change in CSF A $\beta 42$ levels, at least for the non-PSEN1 subjects, is at first glance disappointing from a possible therapeutic perspective, it is not surprising given a similar result in human subjects with AD [24,31]. However, high doses of simvastatin have been shown to reduce both $A \beta 42$ and $\mathrm{A} \beta 40$ in both the CSF and brain homogenates of guinea pig [32]. We have no data on $A \beta 40$ metabolism given that all our CSF samples were assayed by Athena Diagnostics for $A \beta 42$, phospho-tau and total tau; this laboratory did not offer assays for $A \beta 40$. Consequently, our lack of accessibility to $A \beta 40$ levels also precluded study of the effects of statin treatment on $A \beta 42 / A \beta 40$ ratios.

We do not know whether the oppositely directed changes in sAPP $\alpha$ by statins in the PSEN1 and nonPSEN1 subjects are the consequence of a different stage in the development of clinically presymptomatic neurodegeneration in these two groups, whether the mutation itself alters the accessibility of cleavage sites for APP metabolism, or whether there is greater underlying heterogeneity in the non-PSEN1 subjects that favors the observed results.

The phospho-tau levels were normal to begin with in the non-PSEN1 subjects and were not changed by statin therapy. Previous studies [33] observed that simvastatin, but not pravastatin, slightly reduced the levels of phospho-tau-181 in hypercholesterolemic subjects without dementia. Moreover, statin therapy has been reported to reduce neurofibrillary tangle burden found at autopsy [34]. In our studies of PSEN1 subjects, statin therapy reduced the phospho-tau values by $8.3 \%$ approaching significance $(P=0.076)$ but with no significant changes in total tau or A $\beta 42$.

Nevertheless, the average pre-statin phospho-tau level in PSEN1 carriers was already abnormally elevated at the onset of our studies and would be expected to have risen without treatment during the period of the study. Thus, the result that the phospho-tau levels did not rise during the course of our studies may suggest that further tests of statins in a larger group of PSEN1 subjects may be warranted.

As for the non-PSEN1 subjects, the increases in sAPPa after statin therapy are quite substantial and might be one of the factors contributing to the decreased risk of $\mathrm{AD}$ in subjects undergoing long-term statin therapy in several recent long-term trials [9-11].

\section{Neurotoxic effects on $A \beta 42$}

There are many potential mechanisms by which $A \beta 42$ may lead to downstream neurodegeneration. These include direct neurotoxicity $[2,3]$, direct vascular endothelial dysfunction [35] and neuroinflammation [36]. The direct neurotoxic affects of $A \beta 42$ oligomers [2,3] include reductions in glutamatergic synaptic transmission and plasticity and attenuation of excitatory synaptic transmission by decreasing the number of surface AMPA and NMDA receptors associated with a collapse of glutamatergic dendritic spines.

At present, it does not seem possible to detemine the relative neurotoxicities of the various effects of $A \beta 42$ and their relative contributions could differ depending on the stage of disease. However, even if statin therapy does not decrease sAPP $\beta$ and A $\beta 42$ in non-PSEN1 subjects, there remains the possibility that increases in $\alpha$-secretase activity activate a pathway that substantially reduces the neurotoxicity of $A \beta 42$

There is a possible relationship between our findings and recent work on a connection between cellular prion protein $\left(\mathrm{PrP}^{\mathrm{c}}\right)$ and $\mathrm{A} \beta 42$ metabolism [37-38]. For example, $\operatorname{PrP}^{c}$ has been reported to mediate the impairment of synaptic plasticity by $A \beta$ oligomers [37]. According to these authors, the blockade of long-term potentiation may be rescued by anti-PrP antibodies that prevent $A \beta$ oligomers from binding to $\operatorname{PrP}^{c}$ [38]. These studies [3738] conclude that $\operatorname{PrP}^{\mathrm{c}}$ is a mediator of $\mathrm{A} \beta$ oligomerinduced synaptic dysfunction and that $\operatorname{PrP}^{c}$-specific pharmacologic interventions may have therapeutic potential for the treatment of AD. Moreover, studies of memory impairment in a mouse model of $\mathrm{AD}$ have found that the deletion of $\operatorname{PrP}^{\mathrm{c}}$ expression dissociated $\mathrm{A} \beta$ 
accumulation from behavioral impairment in mice, suggesting that the cognitive deficit normally resulting from some aspect of the A 342 cascade selectively requires $\mathrm{PrPc}^{\mathrm{c}}[39]$.

However, even more recently, three groups [40-42] studying different model systems from those utilized by the above authors, although confirming the high avidity of $\mathrm{A} \beta 42$ for $\mathrm{PrP}^{\mathrm{c}}$, failed to confirm any reduction in the neurotoxicity of $A \beta 42$ in the absence of its binding to $\mathrm{PrP}^{\mathrm{c}}$. Clearly, it would be of great interest if it could be determined whether the original results apply to humans. Moreover, $\alpha$-secretase has been reported to be responsible for the physiological processing of $\mathrm{PrP}^{\mathrm{c}}$ in the middle of its toxic sequence [43-45]. Thus, Cisse and Mucke [45] suggest that one way to prevent both $\mathrm{A} \beta$ production and the downstream mediation of $\operatorname{PrP}^{\mathrm{c}}$ might be to increase $\alpha$-secretase activity. We suggest the possibility that a statin-induced increase in $\alpha$-secretase activity could, assuming that the $\mathrm{A} \beta 42-\mathrm{PrP}^{\mathrm{c}}$ link for the neurotoxicity of $A \beta 42$ applies in humans, lead to the reduction of the neurotoxicity of $A \beta 42$ even if its concentration was not reduced. Thus, our recent findings preceding publications about the proposed link between A 342 oligomers and $\mathrm{PrP}^{\mathrm{c}}$ (together with their cleavage by $\alpha$-secretase) may take on added significance, at least for the reduction of $\mathrm{AD}$ risk in non-PSEN1 subjects, depending upon the outcome of the $\mathrm{A} \beta 42-\mathrm{PrP}^{\mathrm{c}}$ controversy.

Moreover, other agents increase the production of $\alpha$ secretase, at least in cell lines. For example, both testosterone [46] and estradiol [47] increase the secretion of the non-amyloidogenic APP fragment, $\operatorname{sAPP} \alpha$, and decrease the secretion of $A \beta$ peptides. It would be of great interest to know whether testosterone and estradiol have similar actions in human males and females, respectively, for carriers of PSEN1 mutations as well as for carriers of ApoE\&4 alleles.

It is also well established that mid-life serum total cholesterol levels are associated with an increased risk of both AD and vascular dementia [48]. Clearly, dementia risk factors are best addressed well before disease symptoms appear. While there is strong evidence that these conclusions apply to non-PSEN1 subjects, it is important to know whether or not they apply to PSEN1 subjects as well.

Although this review has focused on the relationship of putative statin therapy with excess $A \beta 42$ assumed to be part of the cascade that leads to neurodegenerative factors, pleiotropic effects of statins must be considered. For example, others have suggested that the putative beneficial effects of statins might be through the production of nitric oxide at the microvascular endothelial level [5]. Moreover, a recent study suggests that mutations in PSEN1 genes may produce defective lysosomal proteolysis, which could itself represent a basis for pathologic protein accumulations in neuronal cell death leading to the identification of novel therapeutic targets [49].

\section{Conclusion}

Long-term statin therapy in non-PSEN1 hyperlipidemic subjects largely heterozygous for ApoE\&4 produced substantial increases in CSF SAPP $\alpha$. It would be of great interest to know whether this effect, if confirmed in larger studies, contributes to the substantial reduction of risk of $\mathrm{AD}$ shown in several large and long-term prospective studies [24].

It would also be of great interest to know whether presymptomatic subjects with PSEN1 mutations would experience beneficial clinical results given our finding that statins decreased sAPP $\beta$ in such subjects, and that initially elevated CSF phospho-tau levels did not further rise over the 2 to 3 years of statin therapy.

It is the hope of many researchers in this field that RNA interference [50] or the application of microRNA techniques $[51,52]$ will eventually lead to breakthroughs in the correction of the increased risk factors conferred by the early onset $\mathrm{AD}$ mutations as well as the risk of $\mathrm{AD}$ associated with ApoE\&4 alleles. However, such aspirations should not diminish present efforts to pursue some of the current approaches described here.

In this respect, perhaps the most exciting prospect of the work reviewed here are the relatively large $(23.7 \%)$ and statistically robust $(P \leq 0.001)$ increases in SAPP $\alpha$ in our statin-treated asymptomatic subjects who were heterozygous for ApoE\&4 when controlling for statininduced decreases in serum cholesterol levels [18]. If an increase in $\mathrm{SAPP} \alpha$ is a prophylactic target for the prevention of $\mathrm{AD}$, then these studies open the way for both augmentation studies of such effects and to compare the magnitude of the static effects observed here with those of other putative therapeutic agents.

Finally, we note that statin therapy has, in general, not been effective in treatment of established AD. For example, a 2002 randomized placebo-controlled 26-week trial of simvastatin in 44 patients with probable LOAD (genetic associations not specified) found no significant alteration of CSF $A \beta 40$ or $A \beta 42$ levels, but patients with mild AD showed a reduction in CSF A $\beta 40$ that was correlated with a reduction of $24 \mathrm{~S}$-hydroxycholesterol [31]. The Alzheimer's Disease Cholesterol-Lowering Treatment (ADCLT) trial examined the effects of atorvastatin over the course of 1 year in 98 individuals with mild to moderate LOAD and found hypercholesterolemic ApoEc4 carriers with mild to moderate AD were most likely to show modest benefits on the ADAS-Cog after 6 months of treatment [53], but no such positive result was found in the much larger LEADe study encompassing 640 patients over 72 weeks [54]. Similarly, no reduction 
This article is part of a review series on Prevention trials. Other articles in the series can be found online at http://alzres.com/series/ preventiontrials

in the rate of decline in neuropsychological test performance was found among the 5,804 participants aged 72 to 80 years with pronounced vascular risks in the PROSPER study randomized to either receive pravastatin or placebo over a 3-year period of observation [55]. A recent Cochrane review update has therefore maintained its conclusion that statin therapy is of no proven benefit for the prevention of $\mathrm{AD}$ [56]. However, none of these negative results of statin therapy in established $A D$ or in the very elderly with severe vascular risk factors excludes the possibility that statins must be started before neurodegenerative processes are well under way to be effective in reducing risk of $\mathrm{AD}$.

\section{Abbreviations}

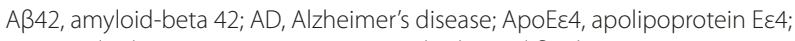
APP, amyloid precursor protein; CSF, cerebral spinal fluid; PrP, prion protein; PrPc, cellular prion protein; PSEN, presenilin; SAPP, soluble amyloid precursor protein.

\section{Competing interests}

The authors declare that they have no competing interests.

\section{Acknowledgments}

We sincerely thank our subjects for their participation in these studies. We thank an anonymous foundation for initial support (DAP, MM). We also thank the families of Edith Marrone, Paul Riley and Peter Simmarano for arranging benefits to help support our work. This work was also supported by grants from the Ontario Research Fund (PGH) and Canadian Institutes of Health Research (ER, PGH). We are especially grateful to two anonymous reviewers whose constructive comments have greatly improved the present drafts.

\section{Author details}

'Department of Neurology, University of Massachusetts Medical School, Worcester, MA 01655, USA. 'Bioinformatics Unit, Information Services and Cell Biology, University of Massachusetts Medical School, Worcester, MA 01655, USA. ${ }^{3}$ Jackson Laboratory, Bar Harbor, ME 04609, USA. ${ }^{4}$ Proteomics and Mass Spectrometry, University of Massachusetts Medical School, Worcester, MA 01655. ${ }^{5}$ Department of Neurology, Mayo Clinic, Scottsdale, AZ 85250, USA. ${ }_{6}^{6}$ University of Toronto, Department of Medicine, Tanz Centre for Research in Neurodegenerative Diseases, Toronto, Ontario, Canada, M5S 3H2. 'Division of Neurology, Department of Medicine, University of Toronto and Toronto Western Hospital, Ontario, Canada. ${ }^{8}$ Department of Clinical Neurosciences, University of Cambridge, Cambridge, CB2 OXY, UK.

\section{Published: 29 October 2010}

\section{References}

1. Sherrington R, Rogaev El, Liang Y, Rogaeva EA, Levesque G, Ikeda M, Chi H, Lin $C$, Li G, Holman K, et al.: Cloning of a gene bearing missense mutations in early-onset familial Alzheimer's disease. Nature 1995, 375:756-760.

2. Walsh,DM, Selkoe DJ: A beta oligomers - a decade of discovery. J Neurochem 2007, 101:1172-1184

3. Li S, Shankar GM, Selkoe DJ: How do soluble oligomers of amyloid betaprotein impair hippocampal synaptic plasticity? Front Cell Neurosci 2010, 4:5.

4. Moonis M, Swearer JM, Dayaw MP, St George-Hyslop P, Rogaeva E, Kawarai T, Pollen DA: Familial Alzheimer disease: decreases in CSF Abeta42 levels precede cognitive decline. Neurology 2005, 65:323-325.

5. Petrie EC, Cross DJ, Galasko D, Schellenberg GD, Raskind MA, Peskind ER Minoshima S: Preclinical evidence of Alzheimer changes: convergent cerebrospinal fluid biomarker and fluorodeoxyglucose positron emission tomography findings. Arch Neurol 2009, 66:632-637.

6. Wolozin B, Kellman W, Ruosseau P, Celesia GG, Siegel G: Decreased prevalence of Alzheimer disease associated with 3-hydroxy-3methyglutaryl coenzyme A reductase inhibitors. Arch Neurol 2000, 57:1439-1443.

7. Jick H, Zornberg GL, Jick SS, Seshadri S, Drachman DA: Statins and the risk of dementia. Lancet 2000, 356:1627-1631

8. Haag MD, Hofman A, Koudstaal PJ, Stricker BH, Breteler MM: Statins are associated with a reduced risk of Alzheimer disease regardless of lipophilicity. The Rotterdam Study. J Neurol Neurosurg Psychiatry 2009, 80:13-17.

9. Cramer C, Haan MN, Galea S, Langa KM, Kalbfleisch JD: Use of statins and incidence of dementia and cognitive impairment without dementia in a cohort study. Neurology 2008, 71:344-350.

10. Sparks DL, Kryscio RJ, Sabbagh MN, Connor DJ, Sparks LM, Liebsack C: Reduced risk of incident $A D$ with elective statin use in a clinical trial cohort. Curr Alzheimer Res 2008, 5:416-421.

11. Heart Protection Study Collaborative Group: MRC/BHF Heart protection study of cholesterol lowering with simvastatin in 20,536 high-rsk individuals: a randomized placebo controlled trial. Lancet 2002, 30:7-22.

12. Zandi PP, Sparks DL, Khachaturian AS, Tschanz J, Norton M, Steinberg M, Welsh-Bomer KA, Breitner JC: Do statins reduce risk of incident dementia and Alzheimer disease? The Cache County Study. Arch Gen Psychiatry 2005, 62:217-224.

13. Arvanitakis Z, Schneider JA, Wilson RS, Bienias JL, Kelly JF, Evans DA, Bennett DA: Statins, incident Alzheimer disease, change in cognitive function, and neuropathology. Neurology 2008, 70:1795-1802.

14. Sparks L: Statins and cognitive function. J Neurol Neurosurg Psychiatry 2009, $80: 1$.

15. Cordle A, Landreth G: 3-Hydroxy-3-methylglutaryl-coenzyme A reductase inhibitors attenuate $\beta$-amyloid-induced microglial inflammatory responses. J Neurosci 2005, 25:299-307.

16. Miida T, Takahashi A, Ikeuchi T: Prevention of stroke and dementia by statin therapy: experimental and clinical evidence of their pleiotropic effects. Pharmacol Ther 2007, 113:378-393.

17. Kojro E, Gimpl G, Lammich S, MarzW, Fahrenholz F: Low cholesterol stimulates the nonamyloidogenic pathway by its effect on the alpha -secretase ADAM 10. Proc Natl Acad Sci U S A 2001, 98:5815-5820.

18. Hinerfeld DA, Moonis M, Swearer JM, Baker SP, Caselli RJ, Rogaeva E, St George-Hyslop P, Pollen DA: Statins differentially affect amyloid precursor protein metabolism in presymptomatic PS1 and non-PS1 subjects. Arch Neurol 2007, 64:1672-1673.

19. Evans BA, Evans JE, Baker SP, Kane K, Swearer J, Hinerfeld D, Caselli R, Rogaeva E, St George-Hyslop P, Moonis M, Pollen DA: Long-term statin therapy and CSF cholesterol levels: implications for Alzheimer's disease. Dement Geriatr Cogn Disord 2009, 27:519-524.

20. Pollen DA: The Quest for the Genetic Origins of Alzheimer's Disease. Oxford University Press; 1996.

21. Ringman JM, Grill J, Rodriguez-Agudelo Y, Chavez M, Xiong C: Commentary on "a roadmap for the prevention of dementia II: Leon Thal Symposium 2008." Prevention trials in persons at risk for dominantly inherited Alzheimer's disease: opportunities and challenges. Alzheimers Dement 2009, 5:166-171.

22. Checler F: Processing of the $\beta$-Amyloid precursor protein and it regulation in Alzheimer's disease. J Neurochem 1995, 65:1431-1444.

23. Mills J, Reiner PB: Regulation of amyloid precursor protein cleavage. J Neurochem 1999, 72:443-460.

24. Hoglund K, Syversen S, Lewczuk P, Wallin A, Wiltfang J, Blennow K: Statin treatment and a disease-specific pattern of beta-amyloid peptides in Alzheimer's disease. Exp Brain Res 2005, 164:205-214.

25. Araki W, Kitaguchi N, Tokushima Y, Ishii K, Aratake H, Shimohama S, Nakamurua S, Kimura J: Trophic effect of beta-amyloid precursor protein on cerebral cortical neurons in culture. Biochem Biophys Res Commun 1991 181:25-71.

26. Small DH, Nurcombe V, Reed G, Clarris H, Moir R, Beyreuther K, Masters CL: A heparin-binding domain in the amyloid protein precursor of Alzheimer's disease is involved in the regulation of neurite outgrowth. J Neurosci 1994, $14: 2117-2127$

27. Morimoto T, Ohsawa I, Takamura C, Ishiguro M, Kohsaka S: Involvement of amyloid precursor protein in function synapse formation in cultured 
hippocampal neurons. J Neurosci Res 1998, 51:185-195.

28. Furukawa K, Barger SW, Blalock EM, Mattson MP: Activation of $\mathrm{K}^{+}$channels and suppression of neuronal activity by secreted beta-amyloid-precursor protein. Nature 1996, 379:74-78

29. Guo Q, Robinson N, Mattson MP: Secreted beta-amyloid precursor protein counteracts the proapoptotic action of mutant presenilin-1 by activation of NF-kappaB and stabilization of calcium homeostatsis. J Biol Chem 1998, 273:12341-12351

30. Meziane H, Dodart JC, Mathis C, Little S, Clemens J, Paul SM, Ungerer A: Memory-enhancing effects of secreted forms of the beta-amyloid precursor protein in normal and amnestic mice. Proc Natl Acad Sci U S A 1998, 95:12683-12688.

31. Simons M, Schwärzler F, Lütjohann D, von Bergmann K, Beyreuther K, Dichgans J, Wormstall H, Hartmann T, Schulz JB: Treatment with simvastatin in normo-cholesterolemic patients with Alzheimer's disease: a 26-week randomized, placebo-controlled, double-blind trial. Ann Neurol 2002, 52:346-350.

32. Fassbender K, Simons M, Bergmann C, Stroick M, Lutjohann D, Keller P, Runz H, Kuhl S, Bertsch T, von Bergmann K, Hennerici M, Beyreuther K, Hartmann T: Simvastatin strongly reduces levels of Alzheimer's disease beta-amyloid disease $\beta$-amyloid peptides $A \beta 42$ and $A \beta 40$ in vitro and in vivo. Proc Natl Acad SciU S A 2001, 98:5856-5861.

33. Riekse RG, Li G, Petrie EC, Leverenz JB, Vavrek D, Vuletic S, Albers JJ, Montine TJ, Lee VM, Lee M, Seubert P, Galasko D, Schellenberg GD, Hazzard WR, Peskind ER: Effect of statins on Alzheimer's disease biomarkers in cerebrospinal fluid. J Alzheimers Dis 2006, 10:399-406.

34. Li G, Larson EB, Sonnen JA, Shofer JB, Petrie EC, Schantz A, Peskind ER, Raskind MA, Breitner JC, Montine TJ: Statin therapy is associated with reduced neuropathologic changes of Alzheimer disease. Neurology 2007. 69:878-885

35. Bennett S, Grant MM, Aldred S: Oxidative stress in vascular dementia and Alzheimer's disease: a common pathology. J Alzheimers Dis 2009, 17:245-257.

36. Agostinho P, Cunha RA, Oliveira C: Neuroinflammation, oxidative stress and the pathogenesis of Alzheimer's disease. Curr Pharm Des 2010, 16:2766-2778

37. Laurén J, Gimbel DA, Nygaard HB, Gilbert JW, Strittmatter SM: Cellular prion protein mediates impairment of synaptic plasticity by amyloid-beta oligomers. Nature 2009, 457:1128-1132

38. Nygaard HB, Strittmatter SM: Cellular prion protein mediates the toxicity of beta-amyloid oligomers: implications for Alzheimer disease. Arch Neurol 2009, 66:1325-1328

39. Gimbel DA, Nygaard HB, Coffey EE, Gunther EC, Laurén J, Gimbel ZA, Strittmatter SM: Memory impairment in transgenic Alzheimer mice requires cellular prion protein. J Neurosci 2010, 30:6367-6374

40. Kessels HW, Nguyen LN, Nabavi S, Malinow R: The prion protein as a receptor for amyloid-beta. Nature 2010, 466:E3-4.

41. Balducci C, Beeg M, Stravalaci M, Bastone A, Sclip A, Biasini E, Tapella L, Columbo L, Manzoni C, Borsello T, Chiesa R, Gobbi M, Salmona M, Forloni G: Synthetic amyloid-beta oligomers impair long-term memory independently of cellular prion protein. Proc Natl Acad Sci U SA 2010, 107:2295-2300

42. Calella AM, Farinelli M, Nuvolone M, Mirante O, Moos R, Falsig J, Mansuy IM, Aguzzi A: Prion protein and Abeta-related synaptic toxicity impairment. EMBO Mol Med 2010, 2:306-314
43. Vincent B, Cisse MA, Sunyach C, Guillot-Sestier MV, Checler F: Regulation of betaAPP and PrPc cleavage by alpha-secretase: mechanistic and therapeutic perspectives. Curr Alzheimer Res 2008, 5:202-211.

44. Cissé MA, Sunyach C, Lefranc-Jullien S, Postina R, Vincent B, Checler F: The disintegrin ADAM9 indirectly contributes to the physiological processing of cellular prion by modulating ADAM10 activity. J Biol Chem 2005, 280:40624-40631

45. Cisse M, Mucke L: Alzheimer's disease: A prion protein connection. Nature 2009, 457:1090-1091.

46. Gouras GK, Xu H, Gross RS, Greenfield JP, Hai B, Wang R, Greengard P: Testosterone reduces neuronal secretion of Alzheimer's beta-amyloid peptides. Proc Natl Acad Sci U S A 2000, 97:1202-1205.

47. Xu H, Gouras GK, Greenfield JP, Vincent B, Naslund J, Mazzarelli L, Fried G, Jovanovic JN, Seeger M, Relkin NR, Liao F, Checler F, Buxbaum JD, Chait BT, Thinakaran G, Sisodia SS, Wang R, Greengard P, Gandy S: Estrogen reduces neuronal generation of Alzheimer beta-amyloid peptides. Nat Med 1998, 4:447-451.

48. Solomon A, Kivipelto M, Wolozin B, Zhou J, Whitmer RA: Midlife serum cholesterol and increased risk of Alzheimer's and vascular dementia three decades later. Dement Geriatr Cogn Disord 2009, 28:75-80.

49. Lee JH, Yu WH, Kumar A, Lee S, Mohan PS, Peterhoff CM, Wolfe DM, Martinez Vicente M, Massey AC, Sovak G, Uchiyama Y, Westaway D, Cuervo AM, Nixon RA: Lysosomal proteolysis and autophagy require presenilin 1 and are disrupted by Alzheimer-related PS1 mutations. Cell 2010, 141:1146-1158.

50. Fire A, Xu S, Montgomery MK, Kostas SA, Driver SE, Mello CC: Potent and specific genetic interference by double-stranded RNA in Caenorhabditis elegans. Nature 1998, 391:806-811.

51. Ambros V: The evolution of our thinking about microRNAs. Nat Med 2008, 10:1036-1040

52. Ruvkun G, Giusto J: The Caenorhabditis elegans heterochronic gene lin-14 encodes a nuclear protein that forms a temporal developmental switch. Nature 1989, 338:313-319.

53. Sparks DL, Connor DJ, Sabbagh MN, Peterson RB, Lopez J, Browne P: Circulating cholesterol levels, apolipoprotein E genotype and dementia severity influence the benefit of atorvastatin treatment in Alzheimer's disease: results of the Alzheimer's Disease Cholesterol-Lowering Treatment (ADCLT) trial. Acta Neurol Scand Suppl 2006, 185:3-7.

54. Feldman HH, Doody RS, Kivipelto M, Sparks DL, Waters DD, Jones RW, Schwam E, Schindler R, Hey-Hadavi J, DeMicco DA, Breazna A; LEADe Investigators: Randomized controlled trial of atorvastatin in mild to moderate Alzheimer disease: LEADe. Neurology 2010, 74:956-964.

55. Trompet $S$, van Vliet $P$, de Craen AJ, Jolles J, Buckley BM, Murphy MB, Ford I, Macfarlane PW, Sattar N, Packard CJ, Stott DJ, Shepherd J, Bollen EL, Blauw GJ, Jukema JW, Westendorp RG: Pravastatin and cognitive function in the elderly. Results of the PROSPER study. J Neurol 2010, 257:85-90.

56. McGuinness B, Craig D, Bullock R, Passmore P: Statins for the prevention of dementia. Cochrane Database Syst Rev 2009:CD003160.

doi:10.1186/alzrt55

Cite this article as: Pollen DA, et al: Prevention of Alzheimer's disease in high risk groups: statin therapy in subjects with PSEN1 mutations or heterozygosity for apolipoprotein E£4. Alzheimer's Research \& Therapy 2010, $2: 31$. 